\title{
Economics of Bio-Hydrogen Production
}

\author{
Parvathy Sathyaprakasan and Geetha Kannan
}

\begin{abstract}
During the past decade, major studies have identified hydrogen as the safest fuel and its demand has been on the rise ever since. This paper looks into the different biological methods of hydrogen production and the economics involved in-order to identify the most economical and environment friendly method of biohydrogen production. A detailed study has been conducted regarding the methods of production, the types of reactors and raw-materials required. The cost requirement of each of the aspects involved in the processes have been looked into. The study proves the Direct Biophotolysis method to be the least favourable in-terms of land requirement and costs and Indirect Biophotolysis and Photofermentation to be amongst the better options available.
\end{abstract}

Index Terms-Bio-hydrogen, direct biophotolysis, indirect biophotolysis, photofermentation, dark fermentation, economics

\section{INTRODUCTION}

During the 1990s hydrogen came to be looked upon as a better source of energy in comparison with other fossil based methods due to the environmental effects that the world had started facing then. Bio-hydrogen was discovered to be the most optimal alternate source of energy. Today the governments in various countries have started taking initiatives in order to promote the production of bio-hydrogen. Despite considerable research and significant progress in methods to improve the rate of biological production of hydrogen, there is very little information available in literature on the economics of large-scale commercial production of bio-hydrogen.

The present paper aims to make economic models of the four major biohydrogen production methods, namely Direct and Indirect Biophotolysis, Photofermentation and Dark Fermentation, in order to predict the most optimum method that can be used on a commercial scale. Direct biophotolysis involves the splitting of water molecules by microalgae in the presence of sunlight. The process involves anaerobic incubation in the dark, in-order to aid the synthesis by activating the enzymes involved, namely hydrogenase [1]. Hydrogenase is extremely sensitive to oxygen and hence the bioreactor used for the process should involve design specifications which are best suited for the required reaction conditions.

Indirect biophotolysis [2] of water evolves hydrogen. The reactions involved are:

$$
6 \mathrm{H}_{2} \mathrm{O}+6 \mathrm{CO}_{2}+\text { light } \longrightarrow \mathrm{C}_{6} \mathrm{H}_{12} \mathrm{O}_{6}+6 \mathrm{O}_{2}
$$

Manuscript received May 25, 2014; revised July 29, 2014.

The authors are with BITS Pilani-Dubai Campus, Dubai (e-mail: parvathys268@hotmail.com)

$$
\begin{gathered}
\mathrm{C}_{6} \mathrm{H}_{12} \mathrm{O}_{6}+2 \mathrm{H}_{2} \mathrm{O} \longrightarrow 4 \mathrm{H}_{2}+2 \mathrm{CH}_{3} \mathrm{COOH}+2 \mathrm{CO}_{2} \\
2 \mathrm{CH}_{3} \mathrm{COOH}+4 \mathrm{H}_{2} \mathrm{O}+\text { light } \longrightarrow 8 \mathrm{H}_{2}+4 \mathrm{CO}_{2}
\end{gathered}
$$

Dark fermentation is the fermentative conversion of organic substrate to hydrogen in the absence of a light source [3].

Photofermentation is the conversion of organic substrate to biohydrogen by photosynthetic bacteria through anaerobic conversion [4], [5]. It takes place in the presence of light unlike dark fermentation.

The various factors that go into designing a bioreactor have been considered for the production of biohydrogen in order to determine the economics involved in the different production methods. We will look into the yield, energy requirements and ease of production in-order to zero in on the most optimal production method.

The economics involved is influenced by the following parameters:

1) Type and amount of culture required

2) Layout of the reactor

3) Capital costs

4) Operating costs

a) Power cost

b) Labor cost

c) Water cost

d) General supplies

The unit cost of the various parameters involved have been considered in U.S Dollars and later converted to AED, in order to analyze the its economic stand in the Middle East.

\section{Cost Estimation}

\section{A. Culture Requirement}

Hydrogen is produced at a rate of 0.07 millimoles per litre-hour by the bio-photolysis process [6]. Consider the plant to be working on a daily basis without any interval. The rate of production during a day would then be 1.68 millimole of hydrogen per litre per day. One mole of hydrogen is equivalent to around $0.86 \mathrm{SCF}$. Then around 60 million moles of hydrogen per day will require 35.7 billion litre of culture. The culture production cost is assumed to be $10 \%$ of labour and general supplies cost.

The production rate of indirect bio-photolysis is 0.36 millimoles of hydrogen/litre-hr. Assuming that the micro-algae can produce $\mathrm{H}_{2}$ at this rate continuously for a 24 hours during a year, the daily production rate is 8.64 millimoles of hydrogen per litre-day. In order to produce 50 million SCF of hydrogen per day, 6.73 million $\mathrm{m}^{3}$ of culture is needed.

Photofermentation hydrogen production rates are reported at 153 millimoles of hydrogen per litre-hour of culture. 
Hence the daily production rate would be 3.672 moles of hydrogen per litre-day [7], [8]. In order to produce 50 million SCF of hydrogen per day at this rate, only 15760 cubic meters of culture is required.

Dark fermentation produces hydrogen at a rate of 121 millimoles per liter hour of culture [9]. Assuming that this production rate can be maintained 24 hours a day, the production rate will corresponds to a daily rate of 2.904 moles of hydrogen per liter. To facilitate producing 50 million SCFD of hydrogen, $19,938 \mathrm{~m}^{3}$ of culture would be required.

\section{B. Layout of the Reactor}

A tubular bio-reactor design is employed for Biophotolysis. It consists of a series of units, where each of these units contain eight tubes, each of which are twenty meters long and four centimetre in diameter. The volume of a tube is 0.025 cubic meters and 8 such tubes would hold 0.201 cubic meters. Given the amount of culture required, 117.5 million tubes are required.

Each of the tube are given 2 metre on each side, giving a length of $24 \mathrm{~m}$. A gap of $4 \mathrm{~cm}$ is left between each tube and a $2 \mathrm{~m}$ berth on either side of the unit giving a total width of $4.5 \mathrm{~m}$ per tubular unit. Hence the total surface area would be $109 \mathrm{~m}^{2}$. Since 117.5 million such units are required, the total area required would be around 19.35 billion $\mathrm{m}^{2}$.

Open photo-bioreactors are employed for Indirect Biophotolysis. This reactor consists of algae contained in ponds and this forms the culture. It produces glucose from carbon dioxide, water and several other nutrients [10]. These algae are further passed into a dark anaerobic reactor in order to yield hydrogen and some amount of acetic acid derivative.

These are further sent to a photo-bioreactor which produces hydrogen by converting the acetic acid derivative [11]. The algae is pumped back into the pond as a recycle mechanism. The optimal depth of an open pond is $25 \mathrm{~cm}$.

Each of these ponds are assumed to be of 100 metres in length, and 10 metres in width. Hence the pond will have a volume of $250 \mathrm{~m}^{3}$. Around 27,000 ponds will be needed to hold 6.73 million litres of culture that is required for the process.

The layout of the ponds will have to include a $2 \mathrm{~m}$ space between each pond. Hence the pond is $102 \mathrm{~m}$ in length, and $12 \mathrm{~m}$ in width, having a surface area of $1,224 \mathrm{~m}^{2}$. This set up would need 8,490 acres of land.

A dark fermentation reactor is also needed. The algae will be moved in stages through dark a fermenters. An assumption is made, that $20 \%$ of the culture is moving through the dark fermenters at a time, representing 1.35 million $\mathrm{m}^{3}$ of culture. An array of 200 cylindrical bioreactors, each 10 metre in height and having a radius of 15 metre, could house such a volume. Allowing for 4 metre on each side of the fermenters for access, the total surface area footprint per fermenters would be $1,150 \mathrm{~m}^{2} .200$ such fermenters should require an additional 57 acres.

A photo-reactor system is required to ferment out the additional hydrogen by the breakdown of acetate. Such a layout will require an additional 2120 acres of land. The total surface area footprint of the open photobioreactor system would therefore be 10,700 acres of land.
The process of photofermentation requires a source of glucose in order to proceed, and its hydrogen production rates are extremely high.

For Dark Fermentation, the experimental setup studied by Chang is utilized. It can hold 3 litres of culture. It is assumed that eight such reactor chambers exist in a typical dark fermentation plant. The total number of 8-reactor units required to hold the 20,600 cubic meters of culture is 858,800 (see Fig. 1).

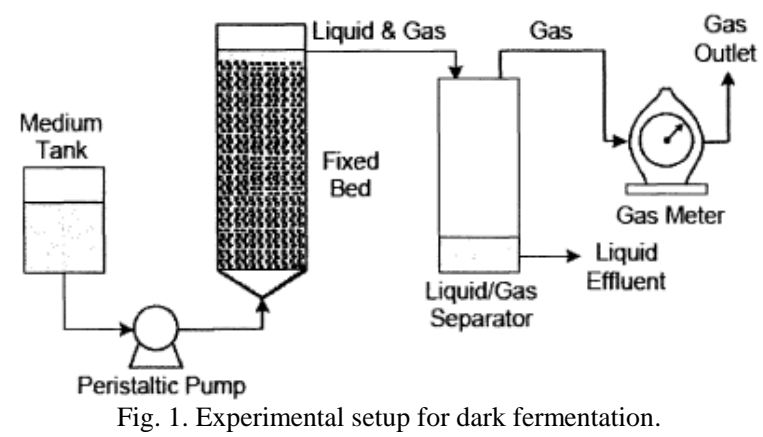

The square length of an 8 reactor unit would be $4 \mathrm{~m}$, and the square area would be $16 \mathrm{~m}^{2}$. Assembling total of 858,000 of these in a land area would require 1,700 acres.

\section{Capital Cost}

For a direct biolysis plant, an area of 19.3 billion $\mathrm{m}^{2}$ would require a capital investment of 1.9 trillion dollars.

Assuming a cost of $\$ 19,999 /$ acre land and subjecting the cost to a scaling factor of 0.9 , the total cost per square meter is $\$ 153$ billion.

For an indirect biophotolysis plant there are three primary components to the capital investment required for this plant: open ponds, dark fermenters and closed photofermenter.

A cost estimate of $\$ 7 / \mathrm{m}^{2}$ for the open pond was put forth by various researchers [6]. Then the total capital investment will be $\$ 240$ million. Assuming the same economy of scale as discussed in the direct biophotolysis, the cost for the open ponds comes down to $\$ 118$ million.

The cost for the dark fermenters is higher than the cost for a pond of $\left(\$ 7 / \mathrm{m}^{2}\right)$ and lower than the cost for a photofermenter $\left(100 / \mathrm{m}^{2}\right)$. Let us assume that the cost for dark fermenters per square metre is $\$ 100 / \mathrm{m}^{2}$, then the cost to build 200 dark fermenters will be $\$ 10.5$ million [6], [12].

Finally, the cost of the closed photofermenter system at the same $\$ 110 / \mathrm{m}^{2}$ is $\$ 172$ with $90 \%$ economy of scale factor.

The total capital investment in this plant is $\$ 300$ million allowing for a $90 \%$ economy of scale. Assuming a 20 year straight line depreciation of this investment, the total capital cost of this approach is therefore $\$ 2.40$ per gigajoule per year. This is a significant savings when compared to direct biophotolysis, whose capital charge per gigajoule per year was $\$ 1,220$.

When it comes to the dark fermentation process we shall consider $\$ 100 / \mathrm{m}^{2}$ price for the bioreactor. Since we need activated carbon for this process, its price also comes into the picture. Consider it to be $\$ 7.19$. At this rate, the total price of activated carbon for an 8 unit reactor would be $\$ 62.60$ per unit. Since such a reactor takes up to 16 square meters, as above, the total cost per square meter for activated carbon is $\$ 3.91$. 
The reactor requires 6.9 million $\mathrm{m}^{2}$ and hence the total capital investment would therefore be $\$ 713$ million. Using the same economy of scale factor as above, this would, in practice, reduce to $\$ 80.5$ million.

\section{Electricity Cost}

Power consumption for such plants will be around $3 \%$ of its total output. The industrial price of electricity is assumed to be $\$ 0.0478 / \mathrm{kWh}$.

\section{E. Water Cost}

Considering $90 \%$ efficiency for the conversion process, 65 million moles of water will be required per day. This is equivalent to 432,000 cubic meters of water annually [6], [13]. Assuming a cost of $\$ 550$ for 100 cubic meters, the annual cost of water used will come up to $\$ 22,000$ for Direct Biophotolysis. This method of cost calculation is also applied for the other three processes.

\section{F. Labour Cost.}

Major studies estimated the total labour cost for a closed plant would be $\$ 16,000$ per hectare. Assuming $10 \%$ of maintenance employee per hectare and a fully loaded cost of $\$ 100,000$ per year, the labour cost will be $\$ 26,000$ per hectare. The bio-reactor covers 1.94 million hectares and the corresponding labour cost is $\$ 50.4$ billion. General Supplies

Tredici estimated the annual cost of general supplies to be $\$ 4000$ annually. If we apply this value over 1.94 million hectares, the cost will be $\$ 7.75$ billion annually.

\section{G. Gas Separation and Handling Costs}

The cost of Pressure Swing Adsorption (PSA) process will represent $3 \%$ of the capital investment. A bio-hydrogen production plant will cost up to $\$ 50$ million to build and so the PSA component will cost $\$ 1.48$ million.

\section{H. Glucose Substrate Cost}

Fermentation processes require glucose as substrate. A little less than 175 million $\mathrm{kg}$ of glucose is needed each year for these processes. Certain companies sell laboratory grade glucose for $\$ 75$ / ton and this corresponds to an annual cost of $\$ 144$ million.

\section{COST COMPARISON}

The direct biophotolysis process has a large land requirement and hence large capital and operating costs. Meanwhile the indirect biophotolysis option performs better than direct Biophotolysis. It is still has the drawback of a large land footprint, but because of improvements in the hydrogen production rate and lesser area of land required, the costs of this plant is more reasonable.

The photofermentation plant has a good production rate but involves difficulty while scaling up. The dark fermentation process is an efficient method due to its high hydrogen production rates and its small footprint. However the most significant cost involved in this process is the cost of the biomass substrate required to drive the process. The critical step involved in cost reduction is the identification of cheaper sources of biomass.
The direct biophotolysis method proves to be an uneconomical choice for hydrogen production. The following bar graphs compare the various costs involved in the other three competitive methods.

It is observed in Fig. 2 that while the power cost is the least for the photofermentation process, it involves a large gas separation expense.

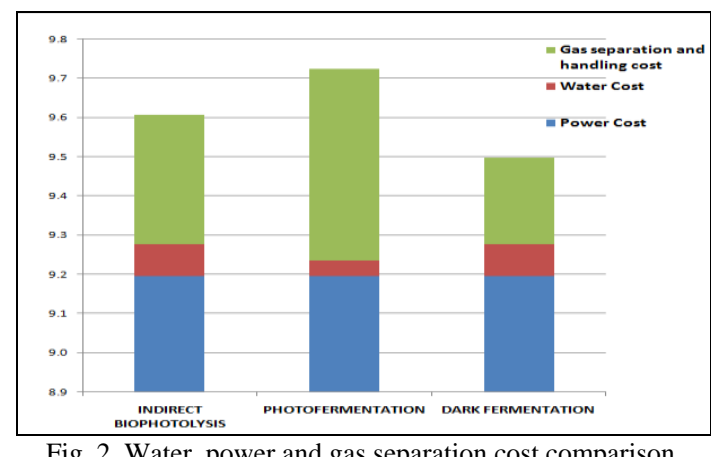

Fig. 3 compares the labour cost, general supplies and culture production costs involved in indirect biophotolysis, photofermentation and dark fermentation processes. The cost is much higher for indirect biophotolysis as it is a continuous process and hence requires more supplies. The labour cost is a direct reflection of the capital costs involved. A large land requirement leads to an increase in the number of maintenance employee and thus leads to increased labour costs.

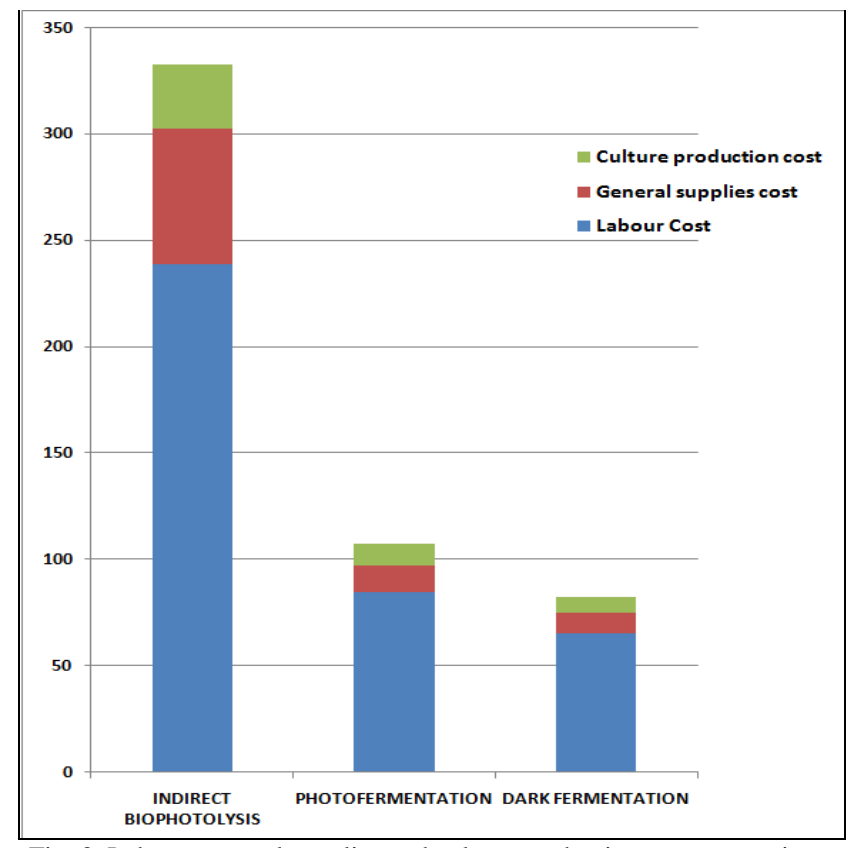

Fig. 3. Labour, general supplies and culture production cost comparison.

Glucose substrate is involved only for the fermentation processes and it can be noted from Fig. 4 that dark fermentation has a higher glucose requirement than photofermentation. It should be noted that, although the other costs involved in the fermentation processes are comparable, the glucose substrate cost solely leads to photofermentation process being more economical over dark fermentation.

Fig. 5, below, summarizes the costs involved and also shows the total operating cost of each of the plants in Dirhams. It also shows the cost of unit kilogram of hydrogen 
fuel obtained from each of the processes that have been discussed. The cost per kilogram of hydrogen is obtained by dividing the cost per gigjoule value by the lower calorific value of hydrogen, $120 \mathrm{MJ} / \mathrm{kg}$.

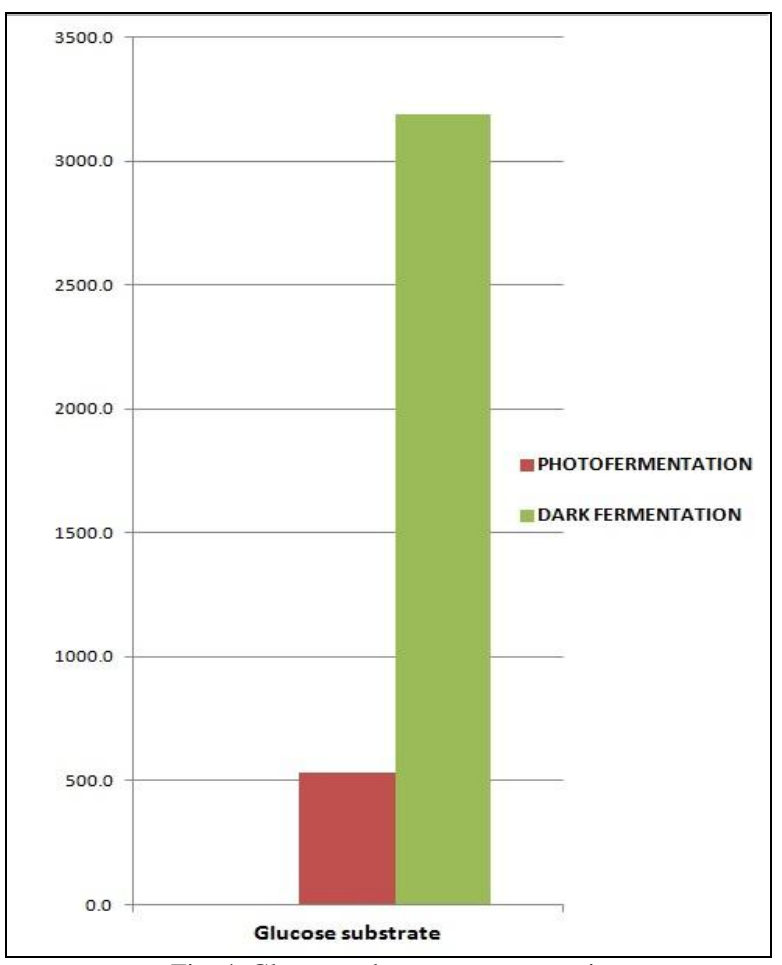

Fig. 4. Glucose substrate cost comparison.

\begin{tabular}{|c|c|c|c|c|c|}
\hline PROCESS & $\begin{array}{c}\text { DIRECT } \\
\text { BIOPHOTOLY- } \\
\text { SIS } \\
\end{array}$ & $\begin{array}{c}\text { INDIRECT } \\
\text { BIOPHOTOLYSIS }\end{array}$ & $\begin{array}{l}\text { PHOTOFERM- } \\
\text { ENTATION } \\
\end{array}$ & $\begin{array}{c}\text { DARK } \\
\text { FERMENTATION }\end{array}$ & $\cos \mathrm{T}$ \\
\hline Item & Amount & Amount & Amount & Amount & Units \\
\hline Power Cost & 8.8 & 9.2 & 9.2 & 9.2 & $\begin{array}{c}\text { Million } \\
\text { AED }\end{array}$ \\
\hline Water cost & 0.1 & 0.1 & 0.0 & 0.1 & $\begin{array}{c}\text { Million } \\
\text { AED }\end{array}$ \\
\hline Labour Cost & 185371.2 & 239.1 & 84.6 & 65.5 & $\begin{array}{c}\text { Million } \\
\text { AED }\end{array}$ \\
\hline $\begin{array}{ll}\text { General supplies } \\
\text { cost }\end{array}$ & 28504.5 & 63.6 & 12.9 & 9.9 & $\begin{array}{c}\text { Million } \\
\text { AED }\end{array}$ \\
\hline $\begin{array}{l}\text { Culture } \\
\text { production cost }\end{array}$ & 21332.4 & 30.2 & 9.9 & 7.4 & $\begin{array}{l}\text { Million } \\
\text { AED }\end{array}$ \\
\hline $\begin{array}{l}\text { Glucose } \\
\text { substrate }\end{array}$ & 0.0 & 0.0 & 529.6 & 3185.1 & $\begin{array}{c}\text { Million } \\
\text { AED }\end{array}$ \\
\hline $\begin{array}{l}\text { Gas separation } \\
\text { and handling cost }\end{array}$ & 84.6 & 0.3 & 0.5 & 0.2 & $\begin{array}{c}\text { Million } \\
\text { AED }\end{array}$ \\
\hline $\begin{array}{l}\text { Subtotal } \\
\text { operating cost }\end{array}$ & 235301.6 & 342.5 & 646.8 & 3277.4 & $\begin{array}{c}\text { Million } \\
\text { AED }\end{array}$ \\
\hline $\begin{array}{l}\text { Contingency } \\
(10 \%)\end{array}$ & 23530.2 & 34.2 & 64.7 & 327.7 & $\begin{array}{c}\begin{array}{c}\text { Million } \\
\text { AED }\end{array} \\
\text {. }\end{array}$ \\
\hline $\begin{array}{l}\text { Total } \\
\text { cost }\end{array}$ & 258831.8 & 376.7 & 711.4 & 3605.1 & $\begin{array}{c}\text { Million } \\
\text { AED }\end{array}$ \\
\hline $\begin{array}{lr}\text { Cost } & \text { per } \\
\text { gigajoule } & \text { of } \\
\text { hydrogen } & \text { f }\end{array}$ & 41084.4 & 59.8 & 112.9 & 572.2 & AED \\
\hline $\begin{array}{l}\text { Cost per kilogram } \\
\text { of hydrogen }\end{array}$ & 4930.1 & 7.2 & 13.6 & 68.7 & AED \\
\hline
\end{tabular}

Fig. 5. Bio-hydrogen production cost comparison.

As mentioned before, it can be noted that the costs involved in direct biophotolysis is considerably higher than the costs of the other processes.

The costs for indirect biophotolysis, photofermentation and dark fermentation are within the same numerical range when compared to direct biophotolysis.

\section{CONCLUSION}

The drawback of the Direct Biophotolysis is the large land area involved which leads to large capital and operating costs rendering it uncompetitive. Improvements in the production rate and lesser land requirement, render the costs of the Indirect Biophotolysis plant as more reasonable.

The Photofermentation plant shows impressive hydrogen production rates in the lab, but the difficulty involved in scaling up the reactor is a major source of concern. The costs that have been observed may be low due to the assumptions made during the analysis. Since similar assumptions were made with all the approaches, a comparison gives useful insight regarding the costs involved.

Dark fermentation process has a high rate of production and comparatively lower land requirement. Identifying carbon sources that are available for lower prices will help cut down the cost involved.

In addition to the costs, the setting up of a hydrogen production plant in the U.A.E will lead to losses due to the unavailability of abundant wet lands. These hydrogen production processes require large quantities of non-saline water and due to the barren topography of the Middle East, the functioning of these plants will not be as efficient as those in nations with abundant water sources.

\section{ACKNOWLEDGMENT}

Ms. Parvathy would like to thank Prof. Dr. R.N Saha, Director of BITS Pilani- Dubai Campus, for his constant encouragement to complete the work successfully.

\section{REFERENCES}

[1] J. Benemann, "Hydrogen biotechnology: progress and prospects," Nature Biotech, pp. 1101-1103, 1996.

[2] J. R. Benemann, "Feasibility analysis of photobiological hydrogen production,” Int. J. Hydrogen Ener., vol. 22, pp. 979-987, 1997.

[3] P. C. Hallenbeck and J. R. Benemann, "Biological hydrogen production; fundamentals and limiting processes," Int. J. Hydrogen Ener., vol. 27, pp. 1185-1193, 2002.

[4] H. Koku, I. Eroglu, U. Gunduz, M. Yucel, and L. Turker, "Aspects of metabolism of hydrogen production by Rhodobacter sphaeroides," Int. J. Hydrogen Ener., vol. 27, 2002.

[5] T. Kondo, M. Arakawa, T. Wakayama, and J. Miyake, "Hydrogen production by combining two types of photosynthetic bacteria with different characteristics," Int. J. Hydrogen Ener., vol. 27, pp. 1303-1308, 2002.

[6] R. J. Resnick, Economics of Bio-Hydrogen Production, June 2004.

[7] K. Nath and D. Das, "Hydrogen from biomass," Cur. Sci., vol. 85, pp. 265-271, 2003.

[8] J. Miyake, M. Miyake, and Y. Asada, "Biotechnological hydrogen production: research for efficient light energy conversion," $J$. Biotechnol., vol. 70, pp. 89-101, 1999.

[9] D. Das and T. N. Veziroglu, "Hydrogen production by biological processes: A survey of literature," Int. J. Hydrogen Ener., vol. 26, pp. 13-28, 2001.

[10] P. C. Hallenbeck and J. R. Benemann, "Biological hydrogen production; fundamentals and limiting processes," Int. J. Hydrogen Ener., vol. 27, pp. 1185-1193, 2002.

[11] J. Benemann, "Hydrogen biotechnology: progress and prospects," Nature Biotech, pp. 1101-1103, 1996.

[12] J. R. Benemann, "Feasibility analysis of photobiological hydrogen production,” Int. J. Hydrogen Ener., vol. 22, pp. 979-987, 1997.

[13] I. Akkerman, M. Janssen, J. Rocha, and R. H. Wijffels, "Photobiological hydrogen production: photochemical efficiency and bioreactor design," Int. J. Hydrogen Ener., vol. 27, pp. 1195-1208, 2002.

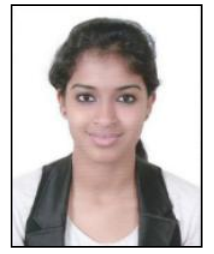

Parvathy Sathyaprakasan was born in India in 1992 She did her schooling in Sharjah at Our Own English High School, Sharjah, UAE. She will be graduating with a B.E.(Hons.) in chemical engineering from BITS Pilani-Dubai Campus, Dubai, UAE in September 2014 She has working experience as an intern at W.S Atkins and Partners Oversees and Sanbook Quality 
Consultancy. Her academic paper titled Impact of Volume Fraction and Particle Size on Thermal Properties of Nano-fluids has been accepted at the International Conference on Heat Transfer and Fluid Flow, to be held in Prague on 21-22 August 2014.

Ms. Parvathy Sathyaprakasan is a member of the Chemical Engineering Student's Association (CheSA).

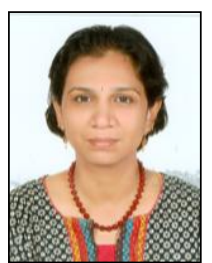

Geetha Kannan earned her bachelor of science degree in general chemistry in 1994 from the Lady Doak College, an autonomous institute affiliated to Madurai Kamaraj University, Madurai, India. She earned her master of science degree in general chemistry from The American College, affiliated to Madurai Kamaraj University in 1996. She did her PhD in Analytical Chemistry in 2000 from the Indian Institute of Technology, Chennai.
She is an assistant professor in the Department of Chemistry at BITS Pilani-Dubai Campus, U.A.E. She teaches chemistry, thermodynamics, biochemical engineering and environmental pollution control. She has five publications under her name, including "An extractive spectrophotometric method for the determination of nitrite using fluoresce in amine isomer i', analytical letters," vol. 33, no. 9 in 2000 and "An indirect method for the determination of sulphur dioxide using methyl red," Microchemical Journal, vol. 65 , pp. $45-49$ in 2000 